\title{
Breves «primeras impresiones» ante un nuevo proceso de reforma del Régimen Local
}

\author{
José Luis Rivero Ysern \\ Catedrático de Derecho Administrativo \\ Universidad Hispalense
}

\begin{abstract}
Sumario: I. INTRODUCCIÓN. II. EL CONTENIDO OBJETIVO DE LA AUTONOMÍA LOCAL. III. LAS FUENTES DEL DERECHO LOCAL. IV. LA PROVINCIA Y LA LLAMADA PLANTA LOCAL. V. LA POTESTAD NORMATIVA LOCAL Y LA ORGANIZACIÓN DEMOCRÁTICA LOCAL. VI. EL SISTEMA DE CONTROL DE LOS ACUERDOS LOCALES. LA POTESTAD DE SUSTITUCIÓN DE LA INACTIVIDAD MUNICIPAL. LA SUPRESIÓN DE LOS MUNICIPIOS. VII. LA PARTICIPACIÓN CIUDADANA Y LOS PROCESOS DE DESCONCENTRACIÓN MUNICIPAL.
\end{abstract}

\section{INTRODUCCIÓN}

Quien suscribe ha perdido la cuenta de los procesos de Reforma del Régimen Local iniciados desde 1985, fecha de publicación de la actual Ley Básica de Régimen Local.

La Ley ha sido reformada, como es sabido, en los años 1999, para introducir el llamado Pacto Local y en el 2003, reforma que venía justificada, a juicio de sus autores, para conseguir la variedad municipal y dotar a los llamados Municipios de Gran Población de un Estatuto especial.

Cuando redacto estas líneas tengo sobre la mesa un nuevo anuncio de reforma, un nuevo Libro Blanco — de primeros de mayo del año 2006-, el Texto de Reforma de algunos Estatutos de Autonomía - el de la Comunidad Autónoma de Cataluña, el de la Comunidad donde vivo, Andalucía, y el de la Comunidad Autónoma de Valencia-. En alguno de ellos se incluyen preceptos específicos sobre temas que, hasta ahora, habían sido objeto de tratamiento en la legislación ordinaria — estatal o autonómica — sobre Régimen Local. Acompañando estos textos, algunos informes de prestigiosas instituciones y especialistas en la materia.

Una serie de circunstancias personales, que no vienen al caso, han provocado la imposibilidad de que estas líneas se publicaran, como era mi deseo en el número 300-301 de la REALA, al que iban dirigidos para atender la amable petición de mi amigo y compañero, el profesor Pedro Escribano. Llego tarde a tan alegre homenaje.

No he renuciado a la publicación de estas impresiones «a bote pronto», sin embargo. Tan reiterados intentos de reforma han provocado en mí, que 
he estado a lo largo de todos estos años hablando a mis alumnos de la Administración local, una cierta desazón. Me he preguntado, puesto que parto de que sabemos qué hay que reformar, si hay una verdadera voluntad política para abordar esa reforma de nuestras administraciones locales.

Mi deseo en estas breves reflexiones es expresar, de forma simple, mi impresión acerca de todo este complejo proceso.

\section{EL CONTENIDO OBJETIVO DE LA AUTONOMÍA LOCAL}

Mi primera reflexión va dirigida a la propia definición de la autonomía local desde el punto de vista competencial. Hace tiempo dije que la tarea de definición de la autonomía local era una tarea inacabada en la LBRL. El sistema de definición competencial de los entes locales de nuestra Ley Básica de Régimen local (trasunto de una Jurisprudencia Constitucional, tributaria a su vez, de una doctrina extranjera), giraba sobre una imprescindible labor de complemento por parte de la legislación sectorial, autonómica y estatal, en la idea de partida, la de competencia-participación de los entes locales.

Pues bien, esa labor de complemento no ha tenido lugar. Con el riesgo que toda generalización lleva consigo, puede afirmarse que la legislación sectorial, estatal y autonómica, no se ha tomado nunca en serio el papel de las Administraciones locales. No se si, quizá, es que no tenemos claro que papel deben asumir estas entidades locales en cada uno de los sectores de la actividad administrativa. La realidad es que no hemos salido aún del sistema de lista de servicios obligatorios, lista que se amplia o reduce sin un modelo claro.

Las reformas estatutarias actualmente en tramitación siguen en la misma línea, con escaso acierto, a mi juicio; todo ello con independencia del absurdo lógico-metodológico de iniciar una reforma de los Estatutos de Autonomía sin una previa reforma constitucional y de la ley Básica de Régimen Local. Una reforma constitucional previa para evitar la reforma constitucional, de facto, vía reforma estatutaria. Y una reforma de la ley Básica, por cuanto entiendo que la Ley Básica de Régimen Local responde al mandato constitucional de definir la garantía institucional de la autonomía local, lo que le concede, sin duda, relevancia constitucional ${ }^{1}$.

No comparto la opinión de algunos expertos y del propio Libro Blanco según la cual el refuerzo del aspecto competencial de la autonomía local reclama una reforma estatutaria que eleve de rango las previsiones de la Ley Básica de Régimen Local.

1 Vid. García Morillo, J.: La configuración constitucional de la autonomía local, Marcial Pons, Madrid, 1998. 
«PRIMERAS IMPRESIONES» ANTE UN NUEVO PROCESO DE REFORMA DEL RÉGIMEN LOCAL

Esta medida considero que rompe la necesaria garantía de un tratamiento igualitario en todo el territorio nacional en orden a la definición de los derechos de los ciudadanos en relación a los servicios de prestación municipal obligatoria.

Con todo parece que la reforma vía estatutos se impone. Así el artículo 90 del Proyecto de Reforma del Estatuto de Autonomía de Andalucía, siguiendo el modelo del artículo 84.1 del Proyecto de Reforma del Estatuto Catalán, garantiza a los municipios un núcleo competencial².

Sin embargo, y en mi modesta opinión estos preceptos añaden poco o nada a lo que ya establecían la Constitución, la Ley Básica de Régimen Local y la jurisprudencia del Tribunal Constitucional. Ni las cláusulas de competencia municipal ni las llamadas a la colaboración, cooperación y coordinación administrativa que se contienen en estos preceptos añaden nada que no sea hacer más complicado el eventual y futuro proceso de reforma de estas ideas y técnicas.

Distinta valoración debe darse, al Libro Blanco para la Reforma del Régimen Local.

Este documento es consciente de que la Carta Europea de la Autonomía Local: define esta autonomía local en positivo no tanto para limitar cuanto para delimitar.

La Carta Europea prescribe que no se trata de preservar una institución protegiéndola, sino de dar contenido a un poder político legitimado democráticamente. Por tanto, el municipio no tiene derechos frente al Estado o las comunidades autónomas sino competencias compartidas con el Estado y las comunidades autónomas.

Tanto la Ley de Bases como los Estatutos son leyes interpuestas que no pueden oscurecer que la autonomía local es autonomía política en el marco de la Constitución y no mera autonomía administrativa en el marco de la ley. La garantía del sistema de gobierno local se encuentra en la Constitución y no en el legislador, sea estatal o autonómico.

La expresión más clara de la posición constitucional del gobierno local es que la cláusula general de competencia municipal tendría anclaje directo en la Constitución y la ordenanza municipal no sería un reglamento cualquiera sino una norma sustantiva que articula jurídicamente una decisión política de tal forma que si el Estado o la comunidad autónoma pormenorizaran reglamentariamente la regulación de una materia de la competencia local, tendría carácter supletorio frente a la aplicación prevalente de la ordenanza.

Hace años nos manifestábamos en parecida posición en la primera edición de nuestro Manual de Derecho local.

\footnotetext{
${ }^{2}$ Font i Llovet, Velasco Caballero, Ortega Álvarez: El régimen local en la reforma de los Estatutos de Autonomía, Centro de Estudios políticos y constitucionales, Madrid, 2006.
} 
Hay que determinar el alcance de la autonomía local no solo por la vía de la definición de ámbitos materiales de actuación atribuibles a los entes locales sino también de potestades y funciones públicas.

En esta línea está la consideración de la potestad de ordenanza como contenido indisponible para la legislación sectorial, autonómica y local, en determinadas materias que recoge el artículo 24 del borrador de Anteproyecto.

Volviendo a los Estatutos, creo que, pese a todo, es positiva la previsión de órganos como el Consejo Catalán de Gobiernos Locales o el Órgano de Relación de la Junta de Andalucía y los Ayuntamientos. Realmente todo va a depender de la composición y funciones de estos órganos; pero si se potencia la representación de las entidades locales en estos órganos y su labor de informe y propuesta adquiere un valor, en una forma u otra, vinculante para la Comunidad Autónoma en la tramitación de proyectos de ley, estaremos ante un instrumento útil para la reforma.

Es posible que a través de este órgano pudiera llegarse a una formulación negociada realista y singularizada de cuáles son los servicios que deben, pero sobre todo pueden hoy por hoy prestar cada municipio de cada Comunidad Autónoma. Es un ejercicio de realismo que, creo, merece la pena intentar. Y lo tiene que intentar cada Comunidad Autónoma estableciendo estándares claros de calidad en la prestación de servicios y medidas financieras adecuadas para esta prestación. E, insisto, municipio por municipio.

Este trabajo va a permitir conocer realmente la situación de nuestros Ayuntamientos y asumir conjuntamente el compromiso de sacar adelante la prestación de servicios y el saneamiento de la Hacienda local.

A mi modo de ver, intentar una reforma de las haciendas Locales sin este previo chequeo es imposible.

Por otra parte, puede que el sistema de lista ponderada de competencias en función de vecinos deje al legislador con la conciencia tranquila de haber definido un mínimo indisponible de competencias municipales, pero la realidad es que esas listas son más una lista de derechos de los ciudadanos (no sólo de los vecinos) que otra cosa. ¿De qué sirven estas declaraciones programáticas si luego esos servicios no pueden prestarse por que no hay medios para ello? ¿Cómo se va a garantizar algo formulado tan genéricamente en los artículos 79 y 80 del Anteproyecto de ley Básica como la suficiencia financiera?

Bienvenida sea, en cualquier caso, la declaración de que las transferencias a las entidades locales tendrán carácter incondicionado así como las medidas de compensación previstas en el artículo 81.

No puede olvidarse que cada municipio tiene una peculiar estructura poblacional en la que la población flotante, la no censada que vive habitualmente 
«PRIMERAS IMPRESIONES» ANTE UN NUEVO PROCESO DE REFORMA DEL RÉGIMEN LOCAL

en municipios cercanos pero trabaja en otro (la población turística asistida, etc.) no permiten previsiones y programaciones sobre la gestión de los servicios con el frío criterio oficial del padrón.

A mi juicio, la redacción del artículo 23 de nuevo borrador de LBRL va en esta línea: no se habla ya de obligación de prestar servicios a los vecinos como de prestar o regular los servicios para garantizar la igualdad de derechos de los ciudadanos.

En suma, nos parece que sería saludable empezar a pensar que en relación con la delimitación del ámbito objetivo de la autonomía municipal, estamos ante un problema de gestión de servicios con eficacia y eficiencia entre distintas administraciones y no ante una búsqueda ingeniosa de definiciones de competencias locales.

Finalmente, recordar e insistir en tres cuestiones: primera que, por imperativo del Derecho comunitario, más concretamente por exigencias del principio de subsidiariedad, se hace ineludible la formulación de una cláusula de competencia universal subsidiaria a favor de los municipios del mismo modo que se reconoce en países con un modelo de Estado similar al nuestro (reforma italiana del régimen local de 1999).

Segundo, la autonomía municipal es, ante todo y sobre todo, una autonomía política. Esta idea ha de llevar a una definición de las competencias locales distinta a la que actualmente efectúa la teoría de la garantía institucional; en otros términos y como ha señalado ya el propio profesor Parejo, la instancia local es el locus preferente para la asignación de competencias, de conformidad con los principios de eficacia y de proximidad de la gestión a los ciudadanos. Esto es lo que enseña la CEAL. Como Sánchez Sáez ha puesto de relieve no hay en el Derecho comparado una cláusula similar a la cláusula de supletoriedad del artículo 149 de nuestra CE. Y, como se recoge en el Informe del Comité Director para la Democracia Local y Regional del Consejo de Europa sobre regionalización —en relación en este caso a Alemania-, las competencias fundamentales de las entidades locales en los Länder respectivos son idénticas y sólo existen diferencias en lo referente a la atribución de tareas determinadas. El principio que rige es que siempre que la ley no disponga expresamente otra cosa, la administración pública es responsabilidad exclusiva de las entidades locales en los límites de su territorio, lo que significa que la competencia general de las entidades locales cubre una amplia gama de tareas y competencias diversas.

\section{LAS FUENTES DEL DERECHO LOCAL}

El proceso de olvido de la legislación sectorial en la definición de las competencias locales ha puesto de manifiesto, junto a lo ya indicado, algo importante: la necesidad de un precepto como el derogado artículo 5 de la 
primitiva redacción de la LBRL. La STC 214/89, de 21 de diciembre, dejó sentado claramente que sólo el Alto Tribunal podía definir de forma interpretativa el sistema constitucional y estatutario relativo a la aplicación del Derecho en la Administración local. Lástima que incomprensiblemente no lo hiciera. Debería hacerlo; nunca es tarde. Presuponer que ese sistema es claro y que en la claridad no cabe interpretación, es algo que se compadece mal con las dudas y conflictos que generan unas leyes, estatales y autonómicas, de espaldas a lo local (vgr., organización, contratos etc.).Definir los criterios de supletoriedad y prevalencia por cada sector de actividad es algo básico por hacer. Esto es especialmente necesario en materias como la ordenación del territorio donde tantos cortes normativos horizontales se producen.

\section{LA PROVINCIA Y LA LLAMADA PLANTA LOCAL}

Observo, cuando se estudia la planta local y, concretamente, los entes locales no territoriales, una contínua alusión, si no confusión, entre entes administrativos y formas gestoras de servicios públicos locales. La figura del Consorcio local es un ejemplo claro de ello: ¿estamos ante un ente local no territorial o ante una forma gestora de servicios o ante una organización de derecho administrativo en la que se dan ambas circunstancias?

¿No es posible que parte de lo que llamamos planta local no sea más que la actividad empresarial pública, el mundo del convenio administrativo y de la gestión de los servicios públicos? Será quizá por ello que sean tan escasos los supuestos prácticos de entes locales no territoriales que se ajusten en cuanto a su naturaleza jurídica a las características que la doctrina y la legislación predican de ellos? ¿Qué tiene que ver todo esto con la llamada planta local? No terminará la planta local en los entes locales territoriales empezando después el mundo empresarial público, la gestión de los servicios públicos, el mundo del contrato público?

¿Por qué no reordenar las funciones de los entes locales territoriales, especialmente la prestación de servicios supramunicipales actualmente en vigor, dando a la provincia su papel y llevando este mundo supuestamente asociativo al ámbito de la gestión de los servicios públicos, al mundo de las formas de gestión y del convenio para la colaboración y la cooperación?

No nos hemos apartado aún del convencimiento de que la Provincia debería haberse formulado de otra forma en la Constitución. El reforzamiento constitucional e incluso estatutario de esta Institución es, sin duda, de los resultados más sorprendentes del proceso de definición constitucional de la Administración local. Es generalizada la opinión de que el papel de la Provincia en la planta local está sobredimensionado y que son poco sustantivas sus competencias. 
«PRIMERAS IMPRESIONES» ANTE UN NUEVO PROCESO DE REFORMA DEL RÉGIMEN LOCAL

Si no cambiamos parte del bloque de la constitucionalidad este tema tiene mal arreglo. Mientras esto sucede, o no, seguimos optando por el vaciamiento fáctico de las competencias provinciales; por «soportar» la inevitable coexistencia de este ente territorial con la estructura indirecta autonómica. Los artículos 25 y 26 del Borrador de Reforma son un ejemplo más de lo que afirmo. Más llamativa resulta aún una afirmación como la que se contiene en la Exposición de Motivos del Anteproyecto de Ley Básica del Gobierno y la Administración Local:

«La Ley parte también de la consideración de que la provincia y su órgano de gobierno, la Diputación provincial, no son algo distinto a los propios municipios, que forman parte de una misma comunidad política local, no son sino propios municipios trabajando conjunta y solidariamente».

Pues bien, si no reformamos la actual LBRL, la Provincia hay que reconocer que carece de competencias. La cooperación con los municipios con insuficiencia de medios para prestar los servicios obligatorios - la supuesta primera competencia básica provincial — no es una competencia, es, simplemente, un principio informador de las relaciones interadministrativas que presupone un claro reparto competencial hoy por hoy inexistente.

La LBRL reconoce además a la Provincia la coordinación de la prestación de servicios públicos municipales a nivel provincial y la prestación de los servicios supramunicipales.

Pues bien para que tales competencias fueran efectivas, de un lado, la Comunidad Autónoma tendría que renunciar a coordinar las políticas municipales y, de otro, tanto los municipios como la Comunidad Autónoma deberían limitarse a cooperar con la Provincia en la prestación de servicios municipales dejando la gran política gestora de servicios supramunicipales en manos de la Provincia. Algo así parece puede deducirse de los artículos 4, 5 y 6 del Borrador de Anteproyecto de Ley básica que establece la posibilidad de limitar el derecho de asociación municipal a la garantía de la autonomía de la Provincia.

Esta interpretación es, por otra parte, la que se infiere de la actual LBRL. El Tribunal Constitucional, en su Sentencia 109/98, concluye que en la provincia, en cuanto entidad local, cabe considerar, como núcleo de su actividad, la cooperación económica a la realización de las obras y servicios municipales. Ese núcleo de actividad se define en el artículo 36.c) de la LBRL en el que, la única competencia sustantiva es la prevista en el apartado c): «la prestación de servicios públicos de carácter supramunicipal, y, en su caso, supracomarcal».

El Libro Blanco es claro en esta misma línea ; en su propuesta séptima del punto II se lee: «Las competencias que la nueva Ley básica atribuya a los municipios que no sean capaces de ejercitar algunos de los municipios 
medianos o pequeños, por falta de capacidad administrativa o de gestión, deben ser ejercidas por las diputaciones provinciales o por las otras Corporaciones de carácter representativo a que hace mención el artículo 141.1 CE, por ser la provincia una entidad local de proximidad y porque sus órganos de gobierno están formados por concejales escogidos en función de los resultados electorales de las elecciones municipales».

Todo ello es realmente complicado partiendo del actual marco político en el que se desarrolla el proceso de constitución de las Diputaciones provinciales. Una modificación como la propuesta precisa un previo refuerzo del papel representativo y democrático de la Provincia, actualmente tan cuestionado dada la forma de elección de los diputados provinciales. La reforma de la Ley de Régimen Electoral General en este punto es inaplazable.

\section{LA POTESTAD NORMATIVA LOCAL Y LA ORGANIZA- CIÓN DEMOCRÁTICA LOCAL}

En este tema creo que vamos ineludiblemente por el buen camino de la mano de la jurisprudencia del Tribunal Constitucional en relación con las modulaciones del principio de reserva de ley en el ámbito local ${ }^{3}$.

La regulación, por ejemplo, en la Ley 57/2003, de la potestad sancionadora de las entidades locales es claro, correcto y fiel trasunto de esta jurisprudencia y abre nuevas responsabilidades a los Ayuntamientos que carecen ya de justificación alguna para no perseguir conductas ciudadanas tan perturbadoras para la convivencia como las conocidas «botellonas».

La fuerte carga democrática del Pleno local es argumento más que sólido para que la Ley haya dado a los Ayuntamientos estas posibilidades de intensificar sus potestades sancionadoras, tributarias o de limitación de los derechos de libre empresa.

La constitucionalidad de esta flexibilización del principio de reserva de ley formal, tan necesaria, empieza a estar sin embargo en entredicho con las veleidades tecnocráticas que la Ley 57/2003 nos ha traído.

La inconstitucional incorporación a la Junta de Gobierno local de miembros no electos - hasta un tercio de su composición - vulnera directamente el artículo $140 \mathrm{CE}$ que encomienda el gobierno municipal al Alcalde y los

\footnotetext{
${ }^{3}$ Vid. Bello Paredes, S.: Las ordenanzas locales en el vigente Derecho español. Alcance y articulación con la normativa estatal y autonómica, INAP, Madrid, 2002; Blasco DíAz, J.L.: Ordenanza municipal y ley, Marcial Pons, Madrid, 2001; Toscano GiL, F.: Autonomía y potestad normativa local, Comares, Granada, 2006; Galán Galán, A.: El Reglamento Orgánico Local, INAP, Madrid, 2004; SÁNCHEZ GoyAnes, E.: La potestad normativa del municipio español, El Consultor de los Ayuntamientos y de los Juzgados, Madrid, 2000.
} 
«PRIMERAS IMPRESIONES» ANTE UN NUEVO PROCESO DE REFORMA DEL RÉGIMEN LOCAL

Concejales. Sin embargo, lejos de rectificar esta previsión, se ratifica en el Borrador de reforma. En algunos borradores esta posible integración no representativa se ha previsto incluso sin limitar el número de miembros no electos a designar en los futuros Consejos de Gobierno locales (en el último borrador se mantiene el porcentaje actual de un tercio, para los municipios que sean capitales de provincia o de Comunidad, y en los de más de 75.000 habitantes, artículo 50).

Con el actual sistema de reparto de competencias entre los órganos municipales es perfectamente viable que, por ejemplo, una ordenanza, en un tema tan jurídica y políticamente sensible como es la materia sancionadora, sea elaborada por la Junta de Gobierno local - que puede delegarla en un grupo de no concejales-. Redactado el proyecto de ordenanza puede ser aprobado en una comisión del Pleno. El proceso terminaría con la delegación del ejercicio de esa potestad en un miembro de la Junta no concejal (art. 127 Ley 57/2003).

La redistribución de competencias entre el Pleno y los órganos ejecutivos especialmente en materia de personal abre, por otra parte, más aún, el proceso de clientelismo político en la contratación y despido de personal en un contexto, especialmente laboral, de despido libre y barato que ni los partidos en el poder desde la Dictadura ni los sindicatos han conseguido frenar. El intento - que no cesa- de sustraer competencias a los Cuerpos con habilitación nacional tampoco ayuda a clarificar este nuevo marco.

So pretexto de defensa de la variedad y la diversidad se generaliza un sistema previsto para las grandes ciudades por la vía, primero de considerar municipios de gran población a municipios que evidentemente no lo son, para después generalizar el proceso de reforma a todos los municipios. Lo que en grandes ciudades podía servir de fundamento -la necesidad de que la gestión recayera en los órganos ejecutivos en mayor medida que venía sucediendo - es difícil de mantener en municipios sin esas características (todo ello por mucho que se haya querido argumentar en el carácter dispositivo del diseño de la Ley 57/2003).

Quien sale curiosamente peor parada en todo este proceso de búsqueda de la variedad municipal es, además de la variedad municipal, la potestad organizatoria local, tan defendida por el Tribunal Constitucional tanto para los Municipios como para las Comunidades Autónomas.

Curiosamente es una ley estatal, prescindiendo no solo de la competencia municipal en materia de organización de los entes locales, sino también de la propia competencia autonómica en la materia, la que uniforma de forma reglamentista hasta el último de los órganos municipales.

Por ello es de valorar positivamente la rectificación que de este proceso de uniformidad se observa en la Disposición Transitoria primera del Borrador: 
«Los municipios que a la entrada en vigor de esta Ley hayan procedido a asumir la organización prevista en el Título X de la Ley 7/1985, de 2 de abril, Reguladora de las Bases del Régimen Local, podrán continuar con dicho régimen en tanto no se oponga, contradiga o resulte incompatible con lo previsto en esta Ley, si bien carecerá de carácter obligatorio la instauración de aquéllos órganos que no resulten de constitución necesaria con arreglo a lo previsto en el Titulo IV de la presente Ley».

\section{EL SISTEMA DE CONTROL DE LOS ACUERDOS LO- CALES. LA POTESTAD DE SUSTITUCIÓN DE LA INAC- TIVIDAD MUNICIPAL. LA SUPRESIÓN DE LOS MUNI- CIPIOS}

Pocas novedades respecto al Régimen vigente presenta en este punto la reforma. Ello es especialmente llamativo por cuanto nos parece uno de los temas más sensibles desde el punto de vista político-jurídico en la vida local. No hay novedades respecto a la sustitución de Entidades Locales ni a la disolución de los órganos de las Entidades Locales.

Esta ausencia de novedades nos merece una valoración positiva. Creemos que, con las salvedades que ya hemos hecho en otro lugar respecto a la inclusión del sistema de disolución de los órganos locales en la LBRL a remolque de la lucha antiterrorista, el sistema de la vigente LBRL respeta los parámetros constitucionales en relación a las relaciones interadministrativas y el juego de la tutela de la Administración estatal y autonómica sobre la local.

La reiteración de estos preceptos desautoriza, al menos de momento, preceptos como el artículo 31.4 de la Ley de Ordenación Urbanística de Andalucía en la redacción dada por la ley 13/2005.

«En los casos de grave incumplimiento por los municipios en el ejercicio de competencias urbanísticas que impliquen una manifiesta afectación a la ordenación del territorio y urbanismo competencia de la Comunidad Autónoma de Andalucía, el Consejo de Gobierno, con audiencia al municipio afectado, dictamen del Consejo Consultivo de Andalucía y previo informe favorable del Parlamento de Andalucía, podrá atribuir a la Consejería competente en estas materias el ejercicio de la potestad de planeamiento que corresponde a los municipios conforme al apartado 1 de este artículo.

El Acuerdo del Consejo de Gobierno delimitará el ejercicio de dicha potestad necesario para restablecer y garantizar las competencias afectadas, las condiciones para llevarlo a cabo, con la intervención del municipio en los procedimientos que se tramiten en la forma que se prevea en el mismo Acuerdo, y el plazo de atribución, que en ningún caso será superior a cinco años desde su adopción. Dicho Acuerdo se pronunciará sobre la suspensión de la facultad de los municipios de firmar convenios de planeamiento a los que se refiere el artículo 30 de la presente Ley, atri- 
«PRIMERAS IMPRESIONES» ANTE UN NUEVO PROCESO DE REFORMA DEL RÉGIMEN LOCAL

buyendo la misma a la Consejería competente en materia de ordenación del territorio y urbanismo».

El precepto comentado viola el principio de proporcionalidad, es contrario a la doctrina del Tribunal Constitucional en la materia - que limita la intervención autonómica en materia urbanística sobre la planificación a la «defensa de intereses de carácter supramunicipal»— y viola el derecho del municipio y de sus vecinos a participar en la toma de decisiones en algo como el planeamiento que, según la STC 159/2001 ó la STC 40/98 es una competencia esencial municipal. La propia STC 51/2004 recuerda que «sobre el Plan urbanístico se proyectan de forma especialmente intensa las exigencias de la autonomía municipal.

Parecida crítica negativa merece el artículo 183.5 de la Ley de Ordenación Urbanística de Andalucía por extender al ámbito de las nulidades la subrogación autonómica en competencias municipales.

\begin{abstract}
«El Ayuntamiento o la Consejería con competencias en materia de urbanismo, en su caso, sin perjuicio de la correspondiente medida de suspensión acordada, dispondrá la inmediata demolición de las actuaciones de urbanización o edificación que sean manifiestamente incompatibles con la ordenación urbanística, previa audiencia del interesado, en el plazo máximo de un mes».
\end{abstract}

En este artículo, la subrogación prevista en la LBRL para supuestos de inactividad en el artículo 60 (STC 11/99 de 11 de febrero) se amplía a los supuestos de obras manifiestamente incompatibles con la ordenación urbanística.

Estas extralimitaciones legislativas tienen su origen, a nuestro juicio, en una falta de control por parte del Estado y la Comunidad Autónoma, vía artículos 65 y 66 de la LBRL., de los actos y acuerdos locales.

Es necesario denunciar la pasividad de las Administraciones de tutela sobre la corrupción municipal; el mirar para otro lado, el no recurrir los acuerdos cuando el municipio era del mismo signo político que el ente de tutela, desautoriza un rasgar de vestiduras y la utilización de mecanismos contrarios a la autonomía local por parte de quienes con cierta frecuencia han sido consentidores de tanto desafuero.

Es necesario reformar, de todas formas, el actual sistema de impugnación de acuerdos locales y es hora ya de hacerlo después de tantos trabajos al respecto. Muy tempranamente me pronuncié sobre este asunto. El actual sistema es disfuncional si se examina desde la perspectiva del control jurisdiccional contencioso administrativo.

De acuerdo con la certera doctrina de la STC 173/2004, se debe ampliar la legitimación de los concejales para impugnar los actos y los acuerdos lo- 
cales incluso de aquellos actos en cuya adopción no han podido, legalmente, estar presentes, incluyendo como objeto del recurso los actos de la Alcaldía y de la Junta de Gobierno local reformándose al respecto la LBRL y la LJCA ${ }^{4}$.

\section{LA PARTICIPACIÓN CIUDADANA Y LOS PROCESOS DE DESCONCENTRACIÓN MUNICIPAL}

Mis últimos trabajos prácticos sobre Administración local se han desarrollado en Sevilla, cooperando en el proceso de reforma de la participación ciudadana y en el diseño del nuevo mapa territorial de nuestra querida ciudad y su organización en distritos.

Esta vivencia práctica me ha llevado al convencimiento de varias cosas. La primera es que para que los municipios sean células políticas vivas hay que acabar con la atonía política y el desinterés, en general, por la Política, en mayúsculas. Esta atonía responde, a buen seguro, a varias y complejas causas. Pero una de ellas, es sin duda, el alejamiento del gobierno local del ciudadano. Las experiencias participativas en otros países y en el nuestro animan a quienes creemos que las ciudades pueden ser algo más que un suelo que se explota urbanísticamente y agujerea, de forma inmisericorde.

Mi segunda conclusión es que la desconcentración administrativa es presupuesto ineludible de la participación.

Y la tercera, que no se puede obligar a nadie a participar. El ciudadano participa cuando se siente oído y atendido, sin demagogia, y cuando observa que le es rentable, en términos de calidad de vida e integración social participar $^{5}$.

La creación del carril bici en Sevilla, fruto de la experiencia participativa y de los presupuestos participativos puestos en marcha en Sevilla ha supuesto una fuerte inversión. Unos vecinos criticaban la medida argumentando que había cosas mucho más importantes que atender. Les dije que era posible que así fuera, pero que me parecería un dinero bien empleado si servía para que ellos llevaran al próximo presupuesto municipal su propuesta de atender lo que ellos consideraban prioritario.

Sevilla mayo de 2006.

\footnotetext{
${ }^{4}$ Flores Domínguez, Luis E.: «La legitimación de los miembros de las corporaciones locales para impugnar los actos y acuerdos de las mismas. Comentario a la STC 173/2004, de 28 de octubre», De la ciudad y otras cosas, Libro homenaje a Enrique Barrero González, Fundación Martín Robles, Sevi1la, 2005, pp. 191 y ss.

5 Vid. S. Fernández Ramos, La información y participación ciudadana en la Administración Local, Bosch, Barcelona, 2005.
} 
«PRIMERAS IMPRESIONES» ANTE UN NUEVO PROCESO DE REFORMA DEL RÉGIMEN LOCAL

\section{POST SCRIPTUM}

Finalizadas estas líneas y a punto de ser enviadas a imprenta, ha llegado a mis manos la Ley 159/de 5 de julio de 2006 de Capitalidad y de Régimen Especial de Madrid.

Sin duda tan importante texto merece un detallado estudio que no voy a realizar, al menos en este momento.

Sin embargo, en esta línea de exponer mis «primeras impresiones», si quiero decir que, tanto este texto como la Ley 1/2006 de 13 de marzo por la que se regula el Régimen Especial del Municipio de Barcelona, marcan una línea a seguir por la legislación general de Régimen local, al menos en orden a la definición de las competencias locales.

Los preceptos atributivos de competencias locales no pueden operar con la indefinición y generalidad con la que vienen operando hasta la fecha. No basta que la Ley Básica recoja un ámbito material para efectuar una atribución de competencias al Municipio.

No es suficiente reconocer al Municipio, vgr, competencias en materia de tráfico o seguridad ciudadana. Hay que desgranar, como hacen estos modernos textos, esa competencia. Hay decir qué se puede hacer con relación a la ordenación del tráfico desde el Ayuntamiento. Y así en materia de ruidos, seguridad ciudadana, medio ambiente etc. Y esto lo debe hacer ya la Ley Básica sin perjuicio, y sin esperar a lo que tenga que decir la legislación sectorial o autonómica al respecto. Al menos así me lo parece. 